\title{
Compromiso social y juego de máscaras y contramáscaras en la dramaturgia de Antonio Hernández Centeno
}

Miguel Ángel García López

\section{(2) OpenEdition}

\section{Journals}

Edición electrónica

URL: https://journals.openedition.org/cher/1085

DOI: $10.4000 /$ cher. 1085

ISSN: 2803-5992

Editor

Presses universitaires de Strasbourg

\section{Edición impresa}

Fecha de publicación: 11 julio 2019

Paginación: 61-75

ISBN: 979-10-344-0046-1

ISSN: 1968-035X

\section{Referencia electrónica}

Miguel Ángel García López, «Compromiso social y juego de máscaras y contramáscaras en la dramaturgia de Antonio Hernández Centeno», reCHERches [En línea], 22 | 2019, Publicado el 04 octubre 2021, consultado el 17 noviembre 2021. URL: http://journals.openedition.org/cher/1085 ; DOI: https://doi.org/10.4000/cher.1085 


\title{
Compromiso social y juego de máscaras y contramáscaras en la dramaturgia de Antonio Hernández Centeno
}

\author{
Miguel Ángel García López
}

\begin{abstract}
A ntonio José Hernández Centeno ${ }^{2}$, guionista y dramaturgo andaluz residente en Madrid, nació en Martos, en 1970. Su interés por el teatro se forjó siendo niño, cuando iba con sus abuelos a las representaciones de los Festivales de España en Martos, en cuyo programa habitualmente había obras de teatro, revistas y zarzuelas (Hernández 2004). La llegada de la Democracia a España a finales de los setenta hizo desaparecer estos festivales, aunque el teatro seguía presente en su pueblo natal a través de la Semana de Teatro, de la cual Hernández Centeno fue un asiduo espectador.

Licenciado en Imagen y Sonido (actual Comunicación Audiovisual) por la Facultad de Ciencias de la Información de la Universidad Complutense de Madrid (1989-1994), Hernández Centeno también estudió Dirección y Dramaturgia en el antiguo Instituto del Teatro de Sevilla (1995-2000), centro de referencia nacional en la formación escénica adscrito al CAT (Centro Andaluz de Teatro) de la Consejería de Cultura de la Junta de Andalucía, y participó en talleres de dramaturgia y escritura dramática con Mariano Barroso, Lluís Pasqual, Sarah Kane, José Sanchis Sinisterra, Antonio Onetti, Rafael Spregelburd y Michel Azama.

En el medio audiovisual ha trabajado como guionista de varias producciones para la televisión, entre las cuales destaca la popular serie Al salir de clase (19992002), así como las miniseries Paquirri (2009) junto a Carmen Pombero, La Duquesa (2010), Mi gitana (2011), Hermanos (2013), los telefilmes El camino de Víctor (2005), No estás sola, Sara (2008-2009) y Días sin luz (2008-2009),

1 Miguel Ángel García López, Departamento de Cuerpo- Escuela Superior de Arte Dramático de Córdoba (España)

2 El autor aparece en la bibliografía citado habitualmente como "Antonio Hernández Centeno", pero también firma sus obras y es citado en ocasiones como "Antonio Hdez. Centeno", "Antonio H. Centeno" y "Antonio Centeno".
\end{abstract}


y los cortometrajes Mi amigo (1996), Feliz aniversario (1997), Las cosas claras y el amor espeso, Ansiedad, Caipiriñas en Ipanema (2013) y Renovarse o morir (2017), los cuales también ha dirigido. También elaboró el guión del largometraje Tierra sin olvido (2004) a partir de su pieza teatral Héroes. Por otra parte, ha sido profesor de Guión de Cine y Televisión durante varios cursos en ESCO (Escuela Superior de Comunicación y Marketing, centro asociado de la Universidad de Gales en Granada).

En el ámbito de las artes escénicas ha desarrollado su labor profesional también desde diversos campos: dirección de escena, producción, gestión cultural, pedagogía y dramaturgia.

Hernández Centeno ha realizado la puesta en escena tanto de textos propios (Cinco, Fin, El día que te vi, Mar de ansias, El día que nació Isaac, Héroes, El gol de Álex) como de ajenos (ayudante de dirección de Etelvino Vázquez en El gran teatro del mundo de Calderón de la Barca para T.N.T.-Territorio de Nuevos Tiempos, director de las lecturas dramatizadas de ¡Vuelve el zorro! de Tomás Afán y de Atrapado (El roto) de José Francisco Ortuño, director de Krámpack de Jordi Sánchez, director de Un horizonte amarillo en los ojos de Gracia Morales). En 1998 fundó la compañía 7Teatro, con la que dirigió algunos de sus primeros montajes y con la que estrenó su obra Cinco. En el año 2000 constituyó junto a Jesús de la Torre y al actor Félix Gómez la productora de teatro y cine Septiembre Producciones Escénicas y Visuales S.L., a la que se incorporó en 2008 la actriz Cynthia Martín; esta empresa ha producido los espectáculos Krámpack de Jordi Sánchez, y El día que te vi, El día que nació Isaac y El gol de Álex de Hernández Centeno.

Entre 2006 y 2008 fue director del Teatro Municipal Maestro Álvarez Alonso de Martos, donde también ha impartido talleres de formación con el grupo de teatro homónimo en el Aula Municipal de Teatro.

$\mathrm{Su}$ trayectoria como dramaturgo se ha enriquecido de toda esta amplia experiencia y se ha ido consolidando a lo largo de más de veinte años, en los que gran parte su obra teatral ha sido galardonada en certámenes de escritura dramática nacionales e internacionales.

En noviembre del año 1998 el autor resultó finalista del II del Concurso de Textos Teatrales para Jóvenes Autores Andaluces "Miguel Romero Esteo" del CAT (Centro Andaluz de Teatro), con su obra Fin; en diciembre de ese mismo año recibió la mención especial del jurado en el I Certamen de Textos Dramáticos de Torreperogil (Jaén) por Cinco, y por esta misma obra recibió en mayo de 1999 el segundo premio en el Festival de Teatro de Alcorcón (Madrid); también en mayo de 1999 ganó II Certamen de Teatro Mínimo "Rafael Guerrero" de Chiclana (Cádiz) con El día que te vi; en noviembre de 1999 ganó la tercera edición del Romero Esteo con La última casa de putas del mundo, publicada con el título de Combatientes; en noviembre de 2005 ganó el Premio de Teatro "Ciudad de Bailén" (Jaén) con Bagdad, Madrid, New York A.M.; en octubre de 2008 recibió la Mención especial del jurado del Certamen Internacional de Teatro Visible con Esperando un héroe; y en el año 2015 recibió 
también una Mención especial en el Certamen Internacional LAM (Leopoldo Alas Mínguez) por su obra Héroes.

El presente artículo pretende acercarnos a la trayectoria de Hernández Centeno como autor dramático, con el fin de dar a conocer algunos de los rasgos distintivos de su escritura dramática y también los elementos comunes más destacados en su dramaturgia. En concreto nos centraremos en el compromiso social, presente tanto en la temática como en los contenidos de su obra, y en el juego de oposición entre máscara y contramáscara que caracteriza a muchos de sus personajes dramáticos.

Para la realización de este estudio hemos tenido el privilegio de disponer de las versiones definitivas de la mayor parte de los textos, que el propio autor nos ha facilitado amablemente para su lectura y estudio. Salvo indicaciones puntuales, nos basaremos únicamente en el texto y no en la representación teatral. Al margen de este artículo dejaremos por tanto su trayectoria como guionista, posible objeto de otro artículo, así como su labor de director de escena con textos de otros autores.

Queremos señalar que para la elaboración del presente artículo hemos dejado fuera expresamente, por su singularidad, cuatro creaciones del autor que vamos a reseñar de manera sucinta: Rojo-blanco-azul, Puertas cerradas, Las bajinas y Baile de máscaras.

En marzo de 2004, con motivo de la celebración del Día Mundial del Teatro en Sevilla, se realizó la lectura dramatizada Rojo-blanco-azul, texto escrito en 2002, dentro del ciclo "Autores vivos" organizado por la asociación francesa Auteurs de l'ombre, con producción de Espacio Meteora y en colaboración con el Ayuntamiento de Sevilla, para dar a conocer la nueva dramaturgia andaluza.

El espectáculo Puertas cerradas, estrenado en 2005 por Entropía Teatro, con producción de la Consejería de Gobernación de la Junta de Andalucía y la Universidad de Jaén, fue escrito por Hernández Centeno, junto a Gracia Morales y Juan Alberto Salvatierra.

El grupo de teatro Maestro Álvarez Alonso estrenó en 2007 en Martos Las bajinas, representación de monólogos creada y dirigida por Hernández Centeno con motivo del Día de la Mujer Trabajadora. Según señala el propio autor en un blog de Martos su intención era: “[...] a través de unos monólogos, lo más de divertidos, demostrar como la mujer, hasta hace bien poco tiempo, por culpa de una sociedad machista, alinastica [sic] y castradora, desconocía por completo su sexo..." (Hernández 2007)

Por último, queremos señalar la existencia de un texto dramático de Hernández Centeno que formaba parte del espectáculo Baile de máscaras (2008), de la Compañía de Danza Rojas y Rodríguez, que el mismo autor dirigió con motivo de la celebración del bicentenario del Levantamiento del 2 de mayo de 1808 en Madrid, y que tampoco hemos incluido en este estudio por la singularidad y la originalidad que presenta al tratarse globalmente de un espectáculo de danza. 
Por lo tanto, y dejando al margen las obras señaladas anteriormente por su particularidad, el corpus dramatúrgico de Hernández Centeno del que partimos para la elaboración de este artículo es el siguiente (indicamos título y fecha de creación $\left.{ }^{3}\right)$ :

Cinco (1997)

Fin (1998)

La última casa de putas del mundo / Combatientes (1999)

De vez en cuando la vida (2001)

Héroes (2002)

Náufragos (2003)

Bagdad, Madrid, New York A.M. (2004)

El día que te vi (2005)

Fotografías, polvo y cenizas (2005)

Un minuto $=60$ segundos (2006)

Mar de ansias (2007)

Buscando respuestas (2009)

¿Próxima cita? Hotel Paraíso (2009)

Lilith, Adán y Eva o la rebelión en el Edén (2009)

Lentejas con chorizo y mucho ajo (2010)

El día que nació Isaac (2010)

El gol de Álex (2015)

Esparta (2017)

Varios de estos textos se corresponden en extensión y duración a lo que consideramos teatro breve e incluso teatro mínimo, también muy presente en la dramaturgia contemporánea andaluza (Orozco 2014). Este tipo de teatro oscila entre la pieza brevísima, de apenas unas líneas, hasta la de cuarenta páginas que “en escena no sobrepasan los noventa minutos” (Díez 2012: 207).

En concreto la obra brevísima Un minuto $=60$ segundos, fue escrita por Hernández Centeno para ser representada precisamente en un minuto, dentro del proyecto dirigido por Alfonso Zurro en la ESAD (Escuela Superior de Arte Dramático) de Sevilla el Día Mundial del Teatro en 2006, junto a las de otros autores andaluces hasta un total de sesenta minipiezas o suspiros de teatro. Le sigue en brevedad la obra Lentejas con chorizo y mucho ajo, de apenas un par de páginas de extensión, también representada dentro de otro proyecto de Alfonso Zurro con motivo del Día Mundial del Teatro, esta vez en una habitación de un hotel en Sevilla en 2010. En la categoría de breve, con apenas unas páginas de extensión, también encontramos los textos De vez en cuando la vida (texto germen de El día que te vi), Buscando respuestas y Fotografías, polvo y cenizas.

3 La fecha de creación de cada obra se corresponde a la señalada por el propio autor, y advertimos aquí que no siempre coincide con otras fechas presentes en la bibliografía, pues en ocasiones no se hace referencia a la fecha de escritura, sino a la fecha de la publicación, a la fecha de la obtención de un galardón, o a la fecha del estreno, sin especificación concreta. 
La duración del resto de sus obras, aunque no suele ser superior a la hora y media de representación, se corresponde con una duración y una extensión convencionales para una obra dramática de producción comercial en nuestro tiempo.

Los textos dramáticos de Hernández Centeno son piezas vivas, en constante revisión y reescritura hasta alcanzar la "versión definitiva" como el propio autor señala en los textos facilitados y que, en ocasiones, se fija años después de la creación original. Esta última versión suele corresponderse al texto del estreno, tras los ensayos, especialmente cuando es el propio autor quien asume la puesta en escena de la obra de teatro, como suele ser habitual. Esta práctica, común en los dramaturgos vinculados a la dirección de escena, pone de manifiesto un compromiso firme del autor con la calidad de su escritura dramática, que conjuga la teatralidad con la verosimilitud que requieren las tablas del escenario para que la pieza pueda ser representada con éxito. Yolanda Ortiz Padilla señala la particularidad que supone ser dramaturgo y director de escena: "No se trata de un dato más, sino de algo que va a modificar y a determinar su concepción dramática. Escriben desde el escenario y para el escenario, sin perder nunca de vista que el teatro es un acto físico, visual.” (Ortiz 2006: 737)

Así pues, Hernández Centeno numera las sucesivas versiones de sus textos, y de este modo lo señala al inicio de El gol de Álex, en su octava versión:

JULIO 2015-SEPTIEMBRE 2016

Esta obra empezó a perpetrarse en un avión de Chicago a New York, fue creciendo en cafeterías de Manhattan, en un tren desafiando el maravilloso paisaje atlántico desde New York a Boston, en Lisboa, en otro tren camino al Algarve, voló a Madrid, pasó algunas horas en Vigo, de nuevo Madrid, siempre dirección a Lisboa, llegó a Martos. Se reescribió, una vez tras otra, en La Calle San Buenaventura de Madrid. Aterrizó en Barcelona, volvió a Madrid y de allí a Valdoviño y Murcia para repasarse un año y unos meses después... (Hernández 2016)

También en alguna ocasión puntual, Hernández Centeno ha desarrollado un texto breve reescribiéndolo hasta dotarlo de una extensión y una duración propias del teatro convencional. Este es el caso de la obra teatro El día que te vi, premiada en el II Certamen de Teatro Mínimo "Rafael Guerrero" de Chiclana (Cádiz) y que desarrolló años después para su estreno comercial en el Teatro Alfil. Una primera y breve versión de este texto la podemos encontrar en el número 16 de la revista Art Teatral. Cuadernos de minipiezas ilustradas, bajo el título De vez en cuando la vida (como el primer verso de la canción homónima de Joan Manuel Serrat) con los personajes Juan y Amada, desarrollados posteriormente como Él y Ella en El día que te vi (Ortega 2001).

Hernández Centeno escribe sus textos con un lenguaje directo, fresco y coloquial, sin artificios innecesarios, tomado de la vida misma. Así lo señala el propio autor en el dossier de Septiembre Producciones para la obra El día que nació Isaac: 
Me gusta escribir sobre lo vivido. Me baso en todo lo sentido y experimentado. La vida vivida es la base de El día que nació Isaac. Por eso la base del teatro que frecuento está en el juego de las relaciones humanas. Experimento y juego con mi propia intimidad y con la intimidad ajena y en ellas me baso para construir personajes, relaciones, situaciones y conflictos [...] La dirección del espectáculo está basada en la verdad, en conocer al fondo a los personajes, en que los actores descubran todos los porqués, que los hagan suyos y toda la historia suene real y sincera. Es la única forma para que la identificación entre el espectador y la historia sea posible. La vida, la verdad y el actor como base del espectáculo, sin estas tres piezas el telón del teatro no se levantaría y El día que nació Isaac no llegaría a nacer. (Hernández et al. 2011: 4)

En muchas ocasiones el lenguaje empleado por sus personajes es duro, descarnado y rotundo, acorde con las situaciones de violencia física y verbal que plasma. Aún en estos casos, el autor logra pulir la dureza de algunos de sus textos con ironía y humor sobre las tablas a través de una acertada puesta en escena que, sin afectar al texto original ni alterarlo, juega con la interpretación para que el espectador no sienta el rechazo esperado y natural, que podría llevarlo a no desear escuchar el texto para evitar sentirse atacado o molesto. Desde la comicidad, textos terribles logran ser asimilados por un público incómodo que no sabe si llorar o reír ante lo que escucha y ve en escena. Un ejemplo muy claro de este recurso de contrastes lo encontramos en un fragmento repetitivo de Lola, la protagonista de El día que te vi. En la puesta en escena dirigida por el propio Hernández Centeno en el Teatro Alfil de Madrid, la actriz ofrece esta intervención con una velocidad de elocución tan elevada que en la repetición logra provocar inicialmente la carcajada del público:

En ese momento, cuando el autor teatral nos ha presentado a la persona, quizá muy reconocible en nuestro entorno o parecida a algunos de nosotros, saca la navaja, y como si se tratara del ojo rasgado de Buñuel, apunta al tuétano, olvida los eufemismos y hace repetir una y otra vez a la actriz que encarna al personaje de Ella en El día que te vi, las siguientes palabras, que son recibidas con cierta sonrisa, al principio, como si de un chiste se tratara, y que entran como un (sic) puñalada envenenada en nuestros estómagos al final:

"Llega a casa. Insiste en que pidamos pizza barbacoa. Llega el repartidor, mientras me toca las tetas en el sofá. Deja de tocarme las tetas y se pone a comerse la pizza. Con las manos pringosas vuelve a tocarme las tetas. Me folla en el suelo del salón. Se corre. Se viste y se va".

Y así, un día y otro día, y así una y otra vez. La sonrisa ya ha desaparecido. Ahora el espectador, llevado de la mano por las repeticiones del texto y por las lágrimas de la actriz, está dentro de la piel del personaje. Está en condiciones de entender realmente qué es eso de la violencia de género y podrá denunciarlo no solo por quedar bien, ni como una afirmación consoladora, sino porque realmente lo siente, porque se ha quitado la venda de los ojos. (Ocaña 2004: 183)

El registro de cada personaje suele corresponderse con su estatus social, aunque el autor no señala demasiado las diferencias culturales o sociales, sino que establece con el lenguaje un terreno de juego común en el que se 
desenvuelven los personajes. Solo en ocasiones puntuales, y porque el autor ha preparado previamente ese terreno socavando con un vacío profundo la situación dramática, podemos leer o escuchar un fragmento poético que, independientemente de su estatus, llena de lírica ese pozo sin fondo en el que el personaje parece ahogarse. Tras ese momento sensible, y por la compensación generada, vuelve la situación al equilibrio propio del final de una tormenta. Encontramos algunos de esos pequeños y efímeros oasis de poesía en varias piezas, por ejemplo, en el monólogo de Carmen de Cinco:

¿Por qué tengo frío... si me estoy quemando?... ¿por qué estoy en este lugar... si no quiero estar?... no entiendo nada de lo que está pasando... me quemo... me congelo... frío... ¿Qué frío?... tu voz se está haciendo más lejana... insegura... se va... ¿ ¿por qué se va?... te veo lejos... te vas... ¿no vas a llamar a nadie?... [...] veo sombras... eres una sombra... como todo este tiempo... una sombra que me perseguía... y me amaba... yo no te amaba... nunca me has conseguido... solo me has obligado... tú querías obligarme a quererte... no lo has conseguido... me has matado... tengo que tener la mente caliente... mi cuerpo está ya frío... eres... egoísta... olvídame... vete... con... tu... mujer... con... tu... amigo... vete... vete... déjame morir... sola... quiero estar... (Hernández 1997: 37-38)

También en Combatientes encontramos un momento poético con final contundente en el personaje de la Puta (Berger et al. 2001).

Hernández Centeno presenta un estilo muy personal y una singular estructuración del texto, con marcada influencia del lenguaje audiovisual, que suele estar presente en la mayoría de sus piezas (Ortiz 2006). Como señala Desirée Ortega (2001), en sus obras, verdadero rompecabezas reconstruido a base de frases cortas por los personajes, combina lo narrativo y lo dramático, el distanciamiento y la identificación; además aprovecha la capacidad evocadora del lenguaje para que sus personajes transiten por el espacio y por el tiempo.

Las temáticas que aborda Hernández Centeno en sus textos son muy variadas, pero tienen en común la humanidad de los personajes y las relaciones que establecen entre ellos, con sus luces y sus sombras. Entre los temas principales: la amistad y el amor; destacan aquellos personajes que se entregan por amor y otros lo rechazan; los primeros parecen perderlo todo a primera vista. $\mathrm{Su}$ sacrificio parece inútil. Sin embargo, son los vencedores, porque saben lo que quieren, han luchado por ello y han sobrevivido. Los otros, acaban destruidos o consumidos por su propio egoísmo. (Ortega 2001)

Con respecto al compromiso, se trata de un compromiso con su tiempo y con su historia que no está reñido con el compromiso con su propia creación artística". (Ortiz 2006: 737). Como señala Juan Mayorga en la introducción a la edición de Combatientes, el teatro de Hernández Centeno precisa "[...] un público que no quiera ahorrarse ni una pizca de malestar." (Berger et al. 2001: 97).

En la reseña al libro Teatro breve andaluz, que recoge una docena de piezas cortas de los autores andaluces entre los que se encuentra Hernández Centeno, la investigadora Virtudes Serrano García pone de manifiesto el compromiso 
ético, social y personal de estos autores, utilizando para ello "una fórmula seria y dolorida o mostrando la mueca burlesca de la comedia”. (Serrano 2010: 37-38).

En este firme compromiso se sitúan los diversos temas de problemática social que son abordados por Hernández Centeno a lo largo de toda su trayectoria dramatúrgica: homofobia, acoso escolar, abusos en la infancia, violencia machista y terrorismo.

En varios de sus textos encontramos muy presente el tema de la homosexualidad, generalmente vinculado a una intensa homofobia ejercida por algunos personajes o por la sociedad misma (Cinco, Fin, Bagdad, Madrid, New York A.M. y El gol de Álex). En otras de sus obras la homosexualidad se muestra a través de las relaciones de los personajes sin el estigma de la discriminación o el rechazo, sino con la naturalidad con la que los personajes viven su propia condición sexual (Héroes y Buscando respuestas). En concreto la temática homosexual aparece ya reflejada en sus primeras obras, con la particular relación del profesor Javier con su alumno Ignacio en Cinco, y el difícil vínculo de Ramón y Jorge en Fin. También está presente la homosexualidad en otras obras además de las aquí citadas, como la delirante Lentejas con chorizo y mucho ajo, con la desconcertante relación entre el Hombre y el Chico.

Por otra parte, en Náufragos un ascensor varado aísla a tres personajes durante el tiempo suficiente para que la tensión del encierro haga salir a flote los asuntos más escabrosos de su pasado y su presente. En el relato de los protagonistas afloran desde lo más profundo diversas situaciones relacionadas con el acoso escolar, los abusos a menores, la violencia machista e incluso el nazismo, que en el aquí y ahora de la reclusión claustrofóbica dentro del ascensor se acaban materializando en una hostilidad verbal y física contra el prójimo que alcanza su máximo de crueldad y de brutalidad en el desenlace de la pieza.

En Bagdad, Madrid, New York A.M., además del contexto general cargado de tensión por los atentados terroristas del 11-S en Nueva York y del 11-M en Madrid, descubrimos el riesgo que la ocultación y el enmascaramiento de identidades puede suponer para la práctica del cibersexo y otras relaciones virtuales en la red a través de la relación virtual de Andrew y Emma. Este personaje también es víctima de la anorexia y la obsesión por una imagen idealizada de sí misma, como sucede con muchas (y muchos) jóvenes adolescentes en la actualidad. Otras temáticas sociales que aparecen en esta obra son la homofobia instaurada en algunos países de cultura árabe a través del viaje de John a la Universidad de Bagdad, y la brecha generacional y la dificultad que supone para las relaciones entre progenitores y vástagos desde la perspectiva de Carmen y su hija Emma, desde la de Alí y su hija Lúa, y desde la de Andrew y su hijo John.

Otro aspecto presente en las piezas de Hernández Centeno es la maternidad y la paternidad bajo diferentes perspectivas: la maternidad deseada de Isabel frente a la negativa de Joaquín en Fotografías, polvo y cenizas, o bien la maternidad subrogada de Una tarde de agosto y de El día que nació Isaac. 
Aunque ya habíamos señalado que en este artículo nos centraríamos en la dramaturgia de Hernández Centeno, no está de más señalar que el autor también ha abordado diversas temáticas comprometidas de hondo calado social en varias de las producciones audiovisuales que ha escrito y/o dirigido: la violencia machista y el maltrato a la mujer en el telefilme No estás sola, Sara (2008-2009); el asesinato de una niña a manos de un pederasta en el telefilme Días sin luz (2008-2009); y la realidad de las personas con VIH en el cortometraje rodado como falso documental Renovarse o morir (2017) de la webserie y el proyecto de salud sexual Indetectables.

El conjunto de circunstancias que plantea Hernández Centeno en sus obras de teatro está, para la mayoría de sus personajes, cargado de mentiras, engaños y falsas apariencias, con seres que viven (o aparentan vivir) una vida que no les corresponde, en ocasiones totalmente opuesta a la que en la realidad es. La verosimilitud con la que el autor presenta este escenario personal está tan bien definida que podemos hablar de auténticos trampantojos en los que los personajes engañan a otros (y a ellos mismos) haciéndoles ver lo que no es verdad.

En un momento dado, estos personajes deciden, generalmente presionados por la tensión de la situación más que por voluntad propia, despojarse de esa falsedad y abrir su corazón a la verdad. Este desvelamiento, generalmente brusco y doloroso, desencadena toda una serie de consecuencias insospechadas y sorprendentes tanto para el resto de los personajes como, sobre todo, para quien lee la obra o presencia el montaje, generando un destacado pico de interés en la curva de tensión dramática que el autor sitúa estratégicamente previo al desenlace final en la estructura de la pieza. El giro dramático que supone la revelación puntual de un personaje sirve, a su vez, de catalizador para que otros personajes se animen a liberar su verdadero ser, en una especie de efecto dominó en el que todos acaban mostrando su verdad.

En el fondo, nos gustaría pensar que el autor también nos está invitando a contagiarnos de este efecto en cadena liberador, de modo que la verdad interior traspase los límites de las páginas del texto y del escenario desde la catarsis: que el espectador y el lector dejen de estar cómodos en el patio de butacas o en su sillón, se remuevan y, tras salir de la función o de la lectura, se atrevan a compartir con alguien cercano una verdad tan íntima que, de otro modo, nunca se hubieran atrevido a contar.

En este contexto de "falsedad de las apariencias" (Ocaña 2004: 181) es donde situamos la contramáscara como recurso dramático. El concepto del juego de máscara y contramáscara (o contra-máscara), acuñado por el pedagogo teatral francés Jacques Lecoq, está muy presente en la dramaturgia de Hernández Centeno, aunque sus personajes no sean interpretados necesariamente con el recurso de las máscaras teatrales. Resulta curioso señalar aquí que Hernández Centeno recibió durante su etapa de formación un curso de creación de 
personaje y máscara contemporánea con Juan Carlos Sánchez, antiguo director del Instituto del Teatro de Sevilla.

Borja Ortiz Ruiz explica el concepto de contramáscara y su aplicación por Lecoq:

Contra-máscara: término empleado por Jacques Lecoq que denomina al personaje que muestra las características físicas y de comportamiento opuestas a las que dibuja la máscara. A través de la contra-máscara, una máscara puede ser actuada poniendo en relieve el personaje contrario al que muestra la propia máscara, lo que ayuda a generar un contraste teatralmente eficaz. [...] En toda máscara de carácter existe una contra-máscara. Actuar la contra-máscara implica desarrollar el personaje desde los rasgos opuestos a los que sugiere la máscara. [...] Este contraste confiere una mayor riqueza y profundidad al personaje. De hecho, dice Lecoq, muchas máscaras obligan a trabajar en esta doble dirección: a favor de ella y a través de la contra-máscara. (Ortiz 2009: 281)

En concreto, Jacques Lecoq lo explica así en su libro El cuerpo poético:

Después de haber llevado a cabo esta primera experiencia de actuación con máscara, propongo a los alumnos que hagan exactamente lo contrario de lo que en apariencia sugiere la máscara. Por ejemplo: una máscara que presenta una evidente cara de "cretino" primero será actuada como tal. El personaje será más bien idiota, tímido, torpe. A continuación consideramos al personaje como sabio, genial, seguro de sí mismo, sumamente inteligente. El actor actúa entonces lo que llamamos la contra-máscara, haciendo aparecer un segundo personaje detrás de la misma máscara y aportando una profundidad mucho más interesante. Descubrimos así que la gente no tiene forzosamente la cara de lo que es y que cada personaje tiene su relieve. Con ciertas máscaras puede llegarse a una tercera etapa de trabajo: que en un mismo personaje, se actúen a la vez la máscara y la contra-máscara. (Lecoq 2003: 91-92)

Este cambio de máscara a contramáscara permite conocer la cara oculta de los personajes, su versión antagónica que, generalmente, suele ser la más auténtica. Y como tal, esta revelación de la verdadera identidad, evocadora de la anagnórisis o el reconocimiento de la tragedia clásica, provoca cambios en las relaciones entre los personajes, genera un punto de inflexión en el desarrollo de la trama, y además funciona habitualmente como un eficaz catalizador del desenlace final.

Como hemos indicado, el cambio suele venir acompañado de un giro dramático en la situación de los personajes en la pieza, es decir, se produce un acontecimiento inesperado o sorprendente que desata la aparición de la contramáscara. En otras ocasiones lo que genera el giro en la trama de la pieza es el efecto dominó por el que empiezan a caer una tras otra, en un juego de acción y reacción, las máscaras de los personajes para ofrecer las contramáscaras. El hecho de que los personajes empiecen, a partir de ese punto de inflexión, a mostrarse radicalmente opuestos a lo que esperábamos provoca que la obra entera adquiera otro tono. Así lo señala Desirée Ortega Cerpa:

En Cinco y Fin, textos reescritos una y otra vez durante el trabajo con los actores, el público siempre comenta desconcertado el giro total en el tono de las obras. Lo 
que parecía una comedia luminosa de pronto se torna un drama sombrío. Pero la vida es así y no la he inventado yo, parece decir Hernández Centeno. Porque la vida a veces se nos muestra con el más hermoso de sus semblantes, nos llena de ilusiones, nos regala sueños, esperanzas, amores, colores, ilusiones, besos, sonrisas, abrazos... y cuando alargamos la mano solo encontramos pesadillas, desilusiones, odios, traiciones, venganzas, desprecios... Como si nos mostrara esa cara oculta que solo descubre cuando estamos desprevenidos. (Ortega 2001)

A continuación, vamos a señalar varias de las obras en las que se muestran estas situaciones en las que los personajes ocultan bajo una máscara aparente una personalidad insospechada o un secreto nunca compartido, y también los momentos en los que los personajes se liberan de la mentira para mostrar su contra-máscara a los demás.

En Cinco encontramos un par de desvelamientos parciales para el personaje de Javier, que al inicio de la pieza revela su homosexualidad a Carlos, a quien más tarde acabará confesándole que siempre ha estado enamorado de él y que por eso lo va a proteger. Aunque el verdadero juego de máscaras se da en el giro inesperado de Carlos en el clímax de la pieza hacia la violencia machista y el sadismo, donde muestra su carácter posesivo y obsesivo, que lo lleva a reaccionar violentamente contra su amante Carmen. También en esta obra encontramos otro personaje que oculta tras una máscara de hermosa apariencia toda su frustración por no ser amada: en la última escena Lucía, tras cinco horas de espera, confiesa a su esposo Carlos cómo lo ama y cómo se ha preocupado de estar siempre perfecta para él, de todos los sacrificios que, inútilmente, hace para que se fije en ella, y también le cuenta su obsesión por estar con él y su temor por sentirse abandonada.

En Fin, el personaje de Antonio no puede seguir mostrando una seguridad que no posee y, ante las dudas y el rechazo que recibe, acaba suicidándose. Este hecho desencadena un sorprendente final en el que Pilar libera su contramáscara de mujer decidida a vengar la muerte de Antonio, logrando incitar al resto del grupo de amigos (Jorge, Ramón, Elsa, Belén y Samuel) a jugar a la ruleta rusa con una pistola peligrosamente cargada.

En Combatientes, Aarón juega en un momento puntual a seducir al personaje de la Puta a través de una máscara de galán romántico que pronto deja caer para mostrar al hombre violento y machista que es, a semejanza de su amigo y compañero Moisés. También durante toda la obra Aaron intenta ocultar que mantiene una relación con Séfora, la esposa de Moisés, y se niega a reconocerlo ante él.

En Héroes, el terrorista Ulises construye una máscara para protegerse en su relación con el joven Iván: se hace llamar Héctor, y le dice que es un geógrafo investigador. Tan solo en la última y comprometedora escena Iván podrá reconocer en persona la verdadera identidad del hombre al que ama.

En Náufragos el concepto de máscara se hace explícito. El autor escribe esta palabra un total de seis veces: cuatro en el texto del personaje de Carmen, una en el de Lidice y una más en una acotación. Los tres personajes se ven sometidos 
a una situación extrema, el encierro en un ascensor, que los lleva a ir mostrando poco a poco su contramáscara como parte de su yo más oculto, aflorando en los respectivos diálogos una personalidad que desconcierta a los demás y que desvela a través de un monólogo otra máscara más antigua y de la que no se pueden liberar fácilmente, forjada en la niñez y la juventud de cada uno de ellos: Jorge el mensajero se muestra como un apuesto estudiante universitario de doctorado, que en esa situación límite acaba revelándose como un joven de ideología nazi, y por debajo de esta máscara y su respectiva contramáscara, descubrimos a un niño gordo y maltratado, víctima de abusos, que intenta esconderse para no sufrir. Carmen la mujer de negocios aparenta ser una respetable dama hecha a sí misma, pero pronto pierde los papeles ante la situación claustrofóbica que están viviendo y se muestra dependiente del alcohol y de un hombre que nunca la quiso como ella a él, dejando entrever al final que "la reina de la mentira" que en su adolescencia se había apartado del amor no ha podido evitar acabar siendo una amante secreta y nada más que eso. Y Lídice, la violonchelista formal y educada, es capaz en plena crisis de ejercer sobre el joven un sadismo brutal que la sitúa a su vez en el polo opuesto de la actitud sumisa y masoquista, adoptada durante su anterior etapa de formación musical en Praga.

El juego de las máscaras en esta obra va más allá de lo habitual en la obra de Hernández Centeno, y podemos situarlo en tres planos distintos: El más profundo se corresponde al pasado que no presenciamos, el que los personajes desvelan al final de la obra en sus respectivos monólogos y cuyas consecuencias son la construcción de su máscara social. Esta máscara social, la más superficial que muestran al inicio de la pieza, es un constructo que funciona como escudo protector de las vulnerabilidades personales. Por último, en un plano intermedio encontramos la contramáscara que se corresponde con su ser más auténtico y verdadero, no por ello el más deseado, pero sí el que se desvela en las situaciones límite por mero instinto de supervivencia.

En la obra Bagdad, Madrid, New York A.M., el anonimato que proporciona internet y las redes sociales permite a Andrew, alto cargo militar estadounidense en la cincuentena, navegar y presentarse bajo la imagen de un joven de diecisiete años; así enmascarado conversa en la red así con Emma, la joven española a la que logra seducir a través del chat desde el principio de la obra. Para afianzar el engaño, Andrew no duda en recurrir a las fotografías de su hijo John cuando era adolescente, y a las de otro joven, que funcionarán como su máscara en esta relación virtual. Andrew se excita y se masturba en varias ocasiones con la imagen verdadera de la joven a través de la pantalla, y ambos llegan a practicar cibersexo. Emma no es consciente del engaño hasta que, por un despiste de Andrew con la cámara en directo, la joven descubre asustada y decepcionada la verdadera identidad hacia el final de la pieza.

En Fotografías, polvo y cenizas no encontramos el juego máscaras y contramáscaras, pero sí un enmascaramiento de la situación: apenas tenemos oportunidad de desvelar el misterio, tan solo se atisba en la pareja en el final 
de la obra la incomodidad generada por la difícil decisión sobre una posible interrupción de un embarazo no deseado.

En El gol de Álex el protagonista se oculta bajo una máscara social de conveniencia que le permite mostrarse ante los demás como el pichichi de la temporada, futbolista heterosexual de éxito, y solamente en la intimidad de la habitación ante Mario, el periodista deportivo que lo admira, es capaz de mostrar su verdadera identidad homosexual.

Es muy frecuente encontrar en las obras de Hernández Centeno, especialmente en las primeras, fragmentos de los diálogos que se entrecruzan de manera que las intervenciones independientes de un personaje se alternan con las de otros, también independientes, generando la impresión de que, por ejemplo, una pregunta de un primer personaje es respondida a continuación en la intervención del segundo personaje, y así sucesivamente, cuando en realidad esta intervención no es una respuesta directa a la cuestión anterior sino que abre una nueva línea argumental o continúa la ya establecida por este segundo personaje.

El rompecabezas de intervenciones de los personajes que el espectador debe reconstruir en su mente, rasgo característico de la escritura teatral de Hernández Centeno, también se podría vincular a una concepción más abierta de lo que entendemos por juego de máscara y contramáscara, o al menos a la idea de enmascaramiento, entendiendo como tal el hecho de desear encubrir o disimular algo. Se trata de cómo el autor logra encadenar intervenciones de varios personajes que no tendrían conexión entre sí aparentemente (máscara), pero que cuando se leen o se escuchan alternadas y entrelazadas pueden aportar una valiosa información subliminal sobre la situación que se plantea en escena (contramáscara). Este juego de misterio permite al lector o espectador curioso entrever lo que no se cuenta explícitamente pero se puede intuir en la escena, o al menos lo que el autor desea que sea intuido de algún modo.

Este recurso, elaborado a conciencia por el autor y evocador de la esticomitia por la que los personajes dialogan en versos alternados, permite que la mirada del lector y el oído del espectador conecte de manera inconsciente entre sí dos hilos de conversación que de por sí son independientes y autónomos, que hibride dos monólogos eslabonados y que construya mentalmente un diálogo, improbable pero totalmente coherente, de personajes que pueden estar en distintos planos espaciales e incluso temporales. El resultado de este entrecruzamiento genera una sinergia por la cual, además de poder seguir dos hilos (o más) de intervenciones particulares, podemos descubrir el mensaje oculto que el autor sugiere y proporciona en la complementariedad de estos hilos sutilmente entrelazados, el cual puede reforzar, matizar o incluso contradecir las expectativas del lector o el espectador, si realmente fuera posible que ambos personajes conversaran entre sí. El autor parece inspirarse para ello en la correlación, la simultaneidad y los diálogos contrapuntísticos presentes en el teatro áureo de Calderón de la Barca.

Finalizamos aquí este artículo, con el deseo de haber colaborado en dar conocer aún más a un autor singular de la dramaturgia andaluza, cuya labor de 
guionista y de autor dramático comprometido con su época se retroalimentan desde hace más de veinte años, permitiéndole una evolución natural hacia nuevas vías de desarrollo tanto de los contenidos como de la forma de sus textos.

En el tintero se nos queda, para otro artículo quizás, el análisis de otro rasgo también característico de este dramaturgo: los territorios comunes y los puentes imaginarios por los que conectamos un personaje de una de sus obras con otro de otra pieza. Se trata de espacios, pero también de objetos, personajes y situaciones que se repiten en diferentes piezas, entretejiendo una maraña en la que se interconecta gran parte de la obra dramática del autor.

\section{Bibliografía}

Berger, J., Ortuño, J. F., [Hernández] Centeno, A., 2001, Doctor, ¿es cierto que el hombre se compone de un 70\% de agua? Atrapado (El roto). Combatientes (introducción a cargo de Juan Mayorga titulada Guerra, sexos y guerra de sexos), Colección "Premio Romero Esteo", núm. 0, Sevilla, Consejería de Cultura.

Díez Ménguez, I. C., 2012, "Bibliografía del teatro breve español en los inicios del siglo XXI”, Signa: revista de la Asociación Española de Semiótica, n²1, Madrid, Centro de Investigación de Semiótica Literaria, Teatral y Nuevas Tecnologías. Departamentos de Literatura Española y Teoría de la Literatura y Filología Francesa, Universidad Nacional de Educación a Distancia, p. 205-347. Hernández Centeno, A., 1997, Cinco, obra teatral, versión definitiva proporcionada por el autor.

Hernández Centeno, A., 2004, "Pregón de la Feria y Fiestas de San Bartolomé 2003", Aldaba, n 16, Martos (Jaén), p. 165-173.

Hernández Centeno, A., 2007, Martos al día, http://www.martosaldia. es/2007/03/14/teatro-las-bajinas/

Hernández Centeno, A., 2016, El gol de Álex, obra teatral, versión número 8 proporcionada por el autor.

Hernández Centeno, A. et al. (Septiembre Producciones), 2011, Dossier del Teatro Fernán Gómez Centro Cultural de la Villa de Madrid, <http:// docplayer.es/amp/55488523-El-dia-que-nacio-isaac.html>.

Lecoq, J. (en colaboración con Carasso, J.-G. y Lallias, J.-C.), 2003, El cuerpo poético. Una pedagogía de la creación teatral, traducción y adaptación al español de Hinojosa, J. y Navarro, M. M., Barcelona, Alba Editorial.

Ocaña Barranco, A. J., 2004, "La falsedad de las apariencias en el Teatro de Antonio Hernández Centeno", Aldaba, n 16, Martos (Jaén), p. 181-183.

Orozco Vera, M. J., 2014, “Los certámenes literarios y la joven dramaturgia. El impulso renovador proyectado por INJUVE y TAETRO” en: Romera Castillo, J. (ed.), Creadores jóvenes en el ámbito teatral $(20+13=33)$ : Actas del XXIII Seminario Internacional del Centro de Investigación de Semiótica Literaria, Teatral y Nuevas Tecnologías, Madrid, Editorial Verbum, p. 76. 
Ortega Cerpa, D., 2001, “Antonio H. Centeno: la Mirada Constante, la Palabra Precisa”, Art Teatral. Cuadernos de minipiezas ilustradas, n 16, Monográfico andaluz coordinado por Andrés Molinari, Valencia, p. 107.

Ortiz Padilla, Y., 2006, “Tres autores andaluces (Gracia Morales, Tomás Afán y Antonio H. Centeno) despiertan al público" en: Romera Castillo, J. (ed.),Tendencias escénicas al inicio del S XXI: Actas del XV Seminario Internacional del Centro de Investigación de Semiótica Literaria, Teatral y Nuevas Tecnologías, Madrid, Visor Libros, p. 735-748.

Ortiz Ruiz, B., 2009, El arte del actor en el siglo XX. Un recorrido teórico y práctico por las vanguardias, núm. 3, Bilbao, Artezblai.

Serrano García, V., 2010, reseña sobre el libro Teatro breve andaluz, Las puertas del drama. Revista de la asociación de autores de teatro, $n^{\circ} 37$, p. 37-38. 